\title{
EL DERECHO A UN MEDIO AMBIENTE SANO: SU RECONOCIMIENTO EN EL CONSTITUCIONALISMO COMPARADO Y EN EL DERECHO INTERNACIONAL
}

\author{
JAUME VERNET \\ Catedrático de Derecho Constitucional \\ Universitat Rovira $i$ Virgili \\ JORDI JARIA \\ Profesor Colaborador de Derecho Constitucional \\ Universitat Rovira $i$ Virgili
}

\author{
SUMARIO \\ I. Introducción. \\ II. Caracterización general del derecho a \\ un medio ambiente sano. \\ III. El derecho a un medio ambiente sano \\ en derecho internacional. \\ IV. El reconocimiento de un derecho a un \\ medio ambiente sano en las constitu- \\ ciones. \\ V. Conclusión.
}

\section{INTRODUCCIÓN}

Decía Guastini que determinados derechos eran "derechos de papel ${ }^{1}$, es decir, derechos sin ninguna eficacia práctica. En algún sentido, esta afirmación se ha aplicado al medio ambiente, como muestra el debate que se produjo en Alemania durante los años ochenta a raíz de la eventual introducción de un derecho relativo a la protección del medio ambiente en la Ley Fundamental. Nos hallamos, efectivamente, ante un derecho del que se duda que puedan

1 Vid. Riccardo GUASTINI, Distinguiendo. Estudio de teoría y metateoría del Derecho, Gedisa, Barcelona, 1999, p. 186. 
derivarse efectos prácticos relevantes y al que se sitúa comúnmente en el ámbito de lo que podríamos llamar los principios rectores (Staatsziele) o los mandatos al legislador (Aufgabenstellungen) ${ }^{2}$.

A partir de esta dimensión objetiva, en tanto que finalidad del Estado o mandato a los poderes constituidos, la protección del medio ambiente iría cobrando una dimensión jurídica realmente efectiva a través de la obra del legislador ${ }^{3}$. Así, mediante la actividad legislativa se irán configurando, ahora ya sí, determinados derechos subjetivos, que no existían hasta ese momento en que el legislador ordinario los define. Tras su configuración legal, el poder judicial podría defender el derecho de las personas a disfrutar de un medio ambiente sano y podríamos hablar ya de una existencia jurídicamente efectiva de dicho derecho.

En este sentido, podría dudarse, desde el punto de vista de la dogmática constitucional, de la existencia de un efectivo derecho a la protección del medio ambiente ex Constitutione. Al análisis de dicha duda y a la posibilidad de construir un contenido autónomo constitucional del derecho a un medio ambiente sano vamos a dedicar este trabajo. Se trata de ver hasta qué punto nos hallamos, dentro del marco constitucional, ante un auténtico derecho, ante un mandato al legislador. Para ello, vamos a intentar asimismo examinar el contexto de dicho derecho tanto en el marco de los instrumentos internacionales como en el del Derecho constitucional comparado, razón por la que hemos adoptado la expresión más común de "derecho a un medio ambiente sano" y no otra de las utilizadas, como "derecho al medio ambiente" o "derecho a un medio ambiente adecuado".

Nuestro punto de partida va a consistir en situar el derecho a un medio ambiente sano dentro de una tipología general de los derechos, a partir de lo cual vamos a intentar su contextualización para terminar en un análisis del derecho, que permita resolver, en algún sentido o en otro, las dudas en cuanto a la posibilidad de otorgarle un contenido efectivo, desde el punto de vista jurídico.

Los derechos en relación con la protección del medio ambiente que, en este estudio, recogemos bajo el concepto unitario de derecho a un medio ambiente sano han sido clasificados habitualmente entre los derechos de tercera generación ${ }^{4}$, es decir, aquellos que afloran en el momento más reciente de de-

2 Sobre las Staatszielbestimmungen y las Aufgabenstellungen en el terreno del Derecho ambiental, vid. Nicolai MÜLLER-BROMLEY, Staatszielbestimmung Umweltschutz im Grundgesetz? Rechtsfragen der Staatszielbestimmung als Regelungsform der Staatsaufgabe Umweltschutz, Eric Schmidt, Berlín, 1990, pp. 111-112.

$3 \mathrm{Vid}$. Jordi JARIA I MANZANO, El sistema constitucional de protecció del medi ambient, Institut d'Estudis Autonòmics, Barcelona, 2005, p. 27ss.

4 Para una síntesis de lo que significan los derechos tradicionales y los derechos sociales o prestacionales, vid. Paolo BARILE, "Nuovi diritti e libertà fondamentali", F. ROCCOBONO (comp.), Nuovi diritti dell'età tecnologica, Giuffrè, Milán, 1991. Respecto a las tres generaciones de derechos, vid. Héctor FIX-ZAMUDO y Salvador VALENCIA CARMONA, Derecho constitucional mexicano y comparado, Porrúa, México, 20012, p. 413 ss. 
sarrollo de la tradición constitucional contemporánea 5 . Los derechos de primera generación serían aquellos derechos clásicos, claramente caracterizados, de carácter individual y que se formulan ante los poderes públicos y como límite a su actividad. En este sentido, desde la perspectiva jurídico-constitucional, acostumbran a caracterizarse como derechos completos que no requieren de desarrollo legislativo y que son directamente exigibles. Se trata de los derechos de libertad.

Una segunda generación de derechos sería la conformada por los llamados derechos sociales, económicos y culturales. Son derechos que, al contrario que los anteriores, a pesar de seguir teniendo un cierto carácter individual, poseen asimismo una dimensión pública, una dimensión colectiva en la que se desarrollan con plenitud. Se caracterizarían por requerir una cierta actividad del Estado, sea a través de la prestación de algún bien o servicio o bien de la limitación de los derechos de libertad de contenido económico.

Estos derechos no sólo se despliegan, por tanto, de manera individual, sino que tienen una dimensión colectiva en la medida que requieren la intervención del Estado. Generalmente, se trata de derechos prestacionales, derechos que reclaman la actividad de los poderes públicos para adquirir contenido efectivo. El derecho a la salud o el derecho a la educación no pueden desarrollarse plenamente si no existen centros sanitarios o educativos. Incluso la tutela judicial efectiva no puede darse si no existe una organización judicial que la preste. Si los anteriores son derechos de libertad, en este caso podemos hablar de derechos de igualdad.

Finalmente, nos encontramos ante lo que se ha dado en llamar derechos de tercera generación, que se basan en los valores sociales emergentes en una sociedad tecnificada como la actual. Estos derechos tienen una fundamentación distinta de los anteriores, en parte, porque constituyen algo parecido a una simbiosis entre los de primera y segunda generación, y, en parte, porque se vinculan a principios constitucionales distintos que sus precedentes. Así, podemos apreciar que, en relación con las características previamente enunciadas, por un lado, tienen un carácter individual (se disfrutan sin relación a una estructura institucional prestadora de servicios, contrariamente a lo que sucede con la salud o la educación), pero al mismo tiempo tienen una dimensión colectiva (en la medida en que el objeto del derecho que se disfruta individualmente tiene un carácter colectivo). Entre estos derechos de tercera

5 Muchos autores se han referido al derecho al medio ambiente como un derecho de tercera generación. En este sentido, cabe citar, a efectos puramente ejemplificativos, a John ALDER y David WILKINSON, Environmental Law \& Ethics, Macmillan, Londres, 1999, p. 379; Nicolás PÉREZ SOLA, "El ordenamiento ambiental y su aplicación a través de las políticas públicas sectoriales", Gerardo RUIZ-RICO RUIZ (coord.), La protección del medio ambiente en el ordenamiento jurídico español, Universidad de Jaén, Jaén, 1995, p. 120; Renato RABBI-BALDI CABANILLAS, "Notas para la fundamentación del derecho ambiental, Anuario de Filosofía Jurídica y Social, n. 13, 1993, p. 270; y José Luis SERRANO MORENO, "Ecología, Estado de Derecho y Democracia”, Anuario de Filosofía del Derecho, Volumen X (nueva época), 1993, p. 165. 
generación se encontraría el derecho a un medio ambiente sano, que se concretaría en una doble exigencia para los poderes públicos: abstención de dañar el objeto del derecho y obligación de protegerlo. Asimismo, esto se proyectaría en la esfera de los particulares, que a su derecho a un medio ambiente sano, añadirían el deber de preservarlo, tal como se recoge en la Constitución española de 1978.

Si el fundamento de los derechos de primera generación es la libertad y el de los de segunda generación, la igualdad, en el caso de los derechos de tercera generación su base es la solidaridad, por ello van íntimamente ligados a deberes correlativos atribuidos a los propios titulares del derecho ${ }^{6}$. La solidaridad como fundamento se explica por el carácter expansivo del bien jurídico protegido que constituye el contenido del derecho, ya que no se trata de la libertad de cada cual (derechos de primera generación) o de las aspiraciones de tal o cual grupo (derechos de segunda generación), sino de un objeto de carácter global que se proyecta hacia todos los seres humanos (actuales y futuros, es decir, tanto a nivel intrageneracional como intergeneracional), lo que, por otra parte, incide en la importancia que el derecho internacional ha tomado en el desarrollo del derecho al medio ambiente sano, contrariamente a lo que había sucedido en la evolución de los derechos de primera y segunda generación, que recibieron su impulso primario y preferente a nivel interno ${ }^{7}$, frente al Estado. Seguramente, la perspectiva internacional ha sido pionera por la incidencia supraestatal de los daños ambientales, lo que implica un esfuerzo de protección planetario del entorno y de la humanidad que en éste se desarrolla, por lo que la óptica tradicional según la cual se necesita acreditar una lesión individual no sirve a los efectos de proteger intereses colectivos como los que el medio ambiente reúne.

6 Vid., particularmente, RABBI-BALDI CABANILLAS, «Notas...” cit., p. 270. Hace énfasis en la importancia del valor de la solidaridad en el ámbito de la protección del medio ambiente

Sobre la importancia del valor de la solidaridad en el ámbito ambiental, vid. Guillermo ESCOBAR ROCA, La ordenación constitucional del medio ambiente, Dykinson, Madrid, 1995, p. 41. Javier DE LUCAS ha dedicado un trabajo específico a esta cuestión: "El principio de solidaridad como fundamento del derecho al medio ambiente, Revista de Derecho Ambiental, n. 12, 1994, pp. $51-70$.

7 Sobre el medio ambiente como espacio global ordenado por el Derecho, vid. Jordi JARIA I MANZANO, El concepte constitucional de medi ambient, Cambra de la Propietat Urbana de Reus, Reus, 2006, p. 78 ss., así como, del mismo autor, El sistema constitucional... cit., p. 21 ss. En cuanto a la influencia del Derecho internacional en este ámbito, debe notarse que, a partir de la Conferencia de Estocolmo, en 1972, el Derecho internacional ambiental se ha desarrollado ràpida y ampliamente, constituyendo una referencia ineludible para los ordenamientos jurídicos estatales. En este sentido, Helene KELLER, "Klimaregime an der Schwelle zum 21. Jahrhundert. Durchbruch dank ökonomischer Instrumente oder Aushöhlung durch Flexibilisierung?", Umweltrecht in der Praxis / Le Droit de l'environnement dans la pratique, 1999, p. 356. En general sobre la evolución del Derecho internacional del medio ambiente después de la Conferencia de Estocolmo, vid. Alexandre Charles KISS, Droit international de l'environnement, Pedone, París, 1989, p. 38 ss. Para una síntesis de las características más relevantes del Derecho internacional ambiental, vid. José JUSTE RUIZ, en "L'evolució del dret internacional del medi ambient", Autonomies, n. 15, diciembre 1992, pp. 45-57. 


\section{CARACTERIZACIÓN GENERAL DEL DERECHO A UN MEDIO AMBIENTE SANO}

Desde el punto de vista de las características o elementos que cabe señalar en relación a como operan el Derecho internacional público y el Derecho constitucional interno en la configuración de los derechos humanos, debe notarse que, en general, cada uno de ellos ha aparecido en un momento histórico y en un lugar geográfico determinados a partir del que se han ido extendiendo a otros lugares hasta lograr un cierto consenso internacional que se ha acabado manifestando en documentos internacionales. En el caso del derecho a un medio ambiente sano, esto no ha sucedido así. El recorrido ha sido distinto. La preocupación por la protección del medio ambiente se ha mostrado primero a nivel internacional como consecuencia de la necesidad de disciplinar el desarrollo tecnológico que a nivel global empezaba a acarrear amenazas significativas para la salud y la vida humanas ${ }^{8}$. Esta preocupación internacional, que se ha manifestado a través del reconocimiento de algún tipo de derecho humano conectado con ella (como, por ejemplo, el principio primero de la Declaración de Río; el artículo 11 del protocolo adicional de la Convención Americana sobre Derechos Humanos en materia de derechos económicos, sociales y culturales; o el artículo 24 de la Carta Africana de Derechos Humanos y de los Pueblos), se ha proyectado posteriormente en las constituciones (en primer lugar, a las de Grecia, Portugal y España, que abrieron el camino para la incorporación generalizada de preceptos sobre la protección del medio ambiente a partir de los años ochenta) ${ }^{9}$. En definitiva,

8 En este sentido, vid. Borja CARDELÚS Y MUÑOZ-SECA, «Técnicas jurídicas para la protección del medio ambiente", Documentación Administrativa, n. 197, enero-marzo 1983, p. 5.

9 En relación con la recepción de un derecho humano en relación con la protección del medio ambiente, vid., por todos, en la doctrina española, Eva JORDÁ CAPITÁN, El Derecho a un Medio Ambiente Adecuado, Aranzadi, Cizur Menor, 2001, p. 159; y Demetrio LOPERENA ROTA, Los principios del Derecho ambiental, Civitas, Madrid, 1998, p. 40. En la literatura internacional, vid., por ejemplo, Justine THORNTON y Silas BECKWITH, Environmental Law, Sweet \& Maxwell, Londres, 1997, p. 46. Las referencias a la literatura sobre el artículo 45 de la Constitución son inabarcables en una nota a pie de página. Citaremos, sin embargo, las monografías dedicadas a la cuestión en el ámbito de la literatura jurídico-constitucional española, a saber: ESCOBAR ROCA, La ordenación constitucional... cit.; Raúl CANOSA USERA, Constitución y medio ambiente, Dykinson, Madrid, 2000 (del mismo autor, puede consultarse, en relación esta cuestión, un trabajo más reciente: "Existe un verdadero derecho constitucional a disfrutar del medio ambiente?, Anuario de Derechos Humanos, tomo 1, vol. 7, 2006, p. 151215); JARIA I MANZANO, El sistema constitucional... cit.; y Gerardo RUIZ-RICO RUIZ, El derecho constitucional al medio ambiente adecuado, Tirant lo Blanch, Valencia, 2000. En relación con la protección del medio ambiente en la Constitución griega, vid. Ioannis KARAKOSTAS y Ionannis VASSILOPOULOS, Environmental Law in Greece, Kluwer-Sakoulas, La Haya-Londres-Boston-Atenas, 1999, p. 36 ss.; y George PAPADIMITRIOU y Maria FLOROU, „Environmental Law in Greece. The Environmental Law System", N. S. J. KOEMAN (ed.), Environmental Law in Europe, Kluwer, La Haya-Londres-Boston, 1999, pp. 301 i 302. En relación con la misma cuestión en la Constitución portuguesa, vid. Diogo FREITAS DO AMARAL y Pedro GARCÍA MARQUES, «Environmental Law in Portugal. The Environmental Law System", KOEMAN, Environmental Law... cit., pp. 464-465; y Maria da Gloria F. D. P. GARCIA, José CUNHAL SENDIM, Pedro MACHETE y Rafael Lucas PIRES, “Portugal”, International Encyclopaedia of Laws. Environmental Law (6), Kluwer, La Haya-Londres-Boston, 2001, p. 16 ss. 
estos derechos emergentes aparecen como una preocupación global que, posteriormente, se concreta en sistemas jurídicos particulares.

A pesar de la tendencia, progresivamente reforzada (particularmente, en la jurisprudencia del Tribunal Europeo de Derechos Humanos, a partir de la Sentencia López Ostra, en 1994), de un reconocimiento en el plano internacional de un cierto derecho en relación con la protección del medio ambiente y el disfrute de un medio ambiente sano, es lo cierto que, en ocasiones, en el plano interno, no nos hallamos ante auténticos derechos jurídicamente exigibles, sino, más bien, ante principios rectores que pretenden orientar la acción de los poderes públicos sin condicionarla a través del control jurisdiccional ${ }^{10}$.

Sin embargo, también los ordenamientos jurídicos estatales (y cada vez en mayor número) responden a la misma tendencia que el Derecho internacional en el sentido de reconocer algún tipo de derecho en relación con la protección del medio ambiente. No obstante, a pesar de los logros de la jurisprudencia del Tribunal Europeo de Derechos Humanos, existe aún una parte significativa de la doctrina que niega que dichos "derechos" sean jurídicamente exigibles, aunque ello, en ocasiones, sea manifiestamente incompatible con la dicción literal de los textos constitucionales y su interpretación sistemática. El caso paradigmático de ello sería la dogmática constitucional y administrativista española, un sector de la cual se ha negado a reconocer algún tipo de exigibilidad jurídica al derecho reconocido en el artículo $45^{11}$.

10 Justine THORNTON y Stephen TROMANS, en "Human Rights and Environmental Wrongs. Incorporating the European Convention on Human Rights: Some Thoughts on the Consequences for UK Environmental Law", Journal of Environmental Law, 11-1, 1999, p. 39, consideran que la Sentencia López Ostra (López Ostra v. España, (1994) 20 EHRR 277) culmina un proceso de «environmentalization" de la Convenio Europeo de Derechos Humanos. Sobre la Sentencia López Ostra, vid., particularmente, el análisis de Juan Antonio CARRILLO DONAIRE y Roberto GALÁN VIOQUE, en "¿Hacia un derecho fundamental a un medio ambiente adecuado? (Comentario en torno al asunto López-Ostra c. España, resuelto por la Sentencia del Tribunal Europeo de Derechos Humanos de 9 de diciembre de 1994)", Revista Española de Derecho Administrativo, n. 86, abril-junio 1995, pp. 271-285. La sentencia mencionada ha sido criticada por Guillermo ESCOBAR ROCA, en "Spain", Robert BLACKBURN y Jörg POLAKIEWICZ (eds.), Fundamental Rights in Europe. The ECHR and Its Member States 1950-2000, Oxford University Press, Oxford, 2001, p. 826. En relación con la protección del medio ambiente en el marco de la Convenio Europeo de Derechos Humanos, vid., asimismo, Lorenzo MARTÍN-RETORTILLO BAQUER, "La defensa cruzada de derechos: la protección del medio ambiente en la jurisprudencia del Tribunal Europeo de Derechos Humanos", Revista Española de Derecho Administrativo, n. 132, 2006, p. 727-746.

11 Vid. José Javier ABAD PÉREZ, "Las Administraciones públicas, el control jurisdiccional y el medio ambiente", Poder Judicial, n. especial IV, p. 35; José María BAÑO LEÓN, "La tutela judicial del medio ambiente y la defensa de los intereses municipales", José ESTEVE PARDO (coord.), Derecho del medio ambiente y administración local, Civitas, Madrid, 1996, p. 614; Raúl CANOSA USERA, "Aspectos constitucionales del Derecho Ambiental", Revista de Estudios Políticos, n. 94 (nueva época), octubre-diciembre 1996, p. 86; Carlos DE MIGUEL PERALES, a Derecho español del Medio Ambiente, Civitas, Madrid, 2000, p. 45; Javier DOMPER FERRANDO, "El medio ambiente: planteamientos constitucionales", Germán GÓMEZ ORFANEL (coord.), a Derecho del medio ambiente, Ministerio de Justicia e Interior, Madrid, 1995, p. 105; Ramón MARTÍN MATEO, Tratado de Derecho Ambiental (I), Trivium, Madrid, 1991, p. 150. 
Igualmente se ha propuesto la concepción sucesiva de los derechos, esto es, la activación de un derecho en dos tiempos. Así, se daría un primer tiempo constitucional en el que se hace un planteamiento que condiciona la regulación infraconstitucional de la materia, pero que no produce efectos desde el punto de vista de la situación jurídica de los particulares. Estos efectos, es decir, el auténtico derecho se daría en un segundo momento, cuando el legislador, de acuerdo con el mandato constitucional, ha previsto los mecanismos para vehicular su exigibilidad jurídica ${ }^{12}$.

Finalmente, también se defiende la posibilidad de encontrar una vía para la exigibilidad jurídica del derecho a un medio ambiente adecuado para el desarrollo de la persona, a través de la legitimación procesal para instar el control de las decisiones de los poderes públicos, en relación con el medio ambiente; así como a la participación pública en la toma de dichas decisiones, materia que ha recibido un impulso importantísimo en Europa a través del Convenio de Aarhus sobre el acceso a la información, la participación del público en la toma de decisiones y el acceso a la justicia ${ }^{13}$.

Más allá de su configuración dogmática, debemos tener en cuenta que su vocación tuitiva, la preservación del entorno físico del ser humano en unas condiciones que permitan no sólo la existencia, sino también el bienestar, de acuerdo con los postulados del constitucionalismo existencial que deriva del Estado social, colisiona con otras aspiraciones del propio Estado social, como es el desarrollo económico ${ }^{14}$. Esto genera un conflicto latente en el ordenamiento jurídico cuando éste admite en su seno estos dos bienes jurídicos contrapuestos en muchas ocasiones, como son la protección del medio ambiente y el desarrollo ${ }^{15}$. En los países menos desarrollados, se ha hablado del derecho al desarrollo, como aspiración legítima que los pueblos y los individuos tienen derecho a exigir y que debe modular, en particular, el grado de protección dado al medio ambiente, asimismo, objeto de un derecho. En este sentido debe considerarse un equitativo reparto de los beneficios (esto es, de los recursos) y de los sacrificios (es decir, de los costes ambientales), en el

12 Vid. Gregorio PECES-BARBA MARTÍNEZ, "El sistema de los derechos fundamentales", Quaderns de Treball, n. 1, Centre d'Estudis de Drets Humans, Bellaterra, 1994, p. 12.

13 Este es el punto de vista defendido en JARIA I MANZANO, El sistema constitucional... cit., p. 191 ss.

14 Para esta cuestión, vid. Jordi JARIA I MANZANO, "El bienestar posible: estado social y protección del medio ambiente", Revista Aranzadi de Derecho Ambiental, núm. 8, 2005, pp. 6182.

15 En relación con el conflicto que se da entre la protección del medio ambiente y la promoción del desarrollo económico existen incontables referencias en la literatura jurídica. Pueden mencionarse, ciñéndose a textos españoles, ABAD PÉREZ, "Las Administraciones públicas..." cit., p. 37; CANOSA USERA, "Aspectos constitucionales...” cit., p. 81; Efraín FERNÁNDEZ MARTÍNEZ, "La protección jurídica del medio ambiente", GÓMEZ ORFANEL, Derecho del medio ambiente cit., p. 166; JORDANO FRAGA, La protección del derecho a un medio ambiente adecuado, J. M. Bosch, Barcelona, 1995, p. 109; y SERRANO MORENO, Ecologia y Derecho: principios de Derecho Ambiental y Ecología jurídica, Comares, Granada, 1992, p. 52. La jurisprudencia constitucional tuvo ocasión de manifestarse en relación con ello en la STC 64/1982, de 4 de noviembre, FJ 2. 
que la perspectiva de los países desarrollados pueda coincidir con la óptica de los países en vías de desarrollo.

La Declaración de Río es paradigmática tanto en el reconocimiento simultáneo del derecho a un medio ambiente sano o adecuado y del derecho al desarrollo, así como a su eventual incardinación en un proyecto social global, que se designa con la noción de desarrollo sostenible ${ }^{16}$. En el marco del desarrollo sostenible, que, de acuerdo con el llamado Informe Bruntland (1988) consiste en «aquél que satisface las necesidades del presente, sin poner en peligro la capacidad de las generaciones futuras de satisfacer sus propias necesidades ${ }{ }^{17}$. De acuerdo con ello, los dos bienes jurídicos deben desplegarse armónicamente, con lo que el medio ambiente protegido incorpora la posibilidad del desarrollo, asimismo objeto de un derecho (como pone de manifiesto, significativamente, el principio tercero de la Declaración de Río).

A nivel internacional, pues, se detecta no sólo la progresiva consolidación del derecho a un medio ambiente sano o adecuado, que, poco a poco, va teniendo efectos a nivel interno a pesar de las reservas que se plantean desde un punto de vista dogmático, sino, asimismo, su configuración el marco de un proyecto humano global que prevé, del mismo modo, la satisfacción del derecho al desarrollo en atención a la situación de pobreza que azota buena parte de la superficie del planeta y a la que debe responderse de algún modo.

Esta mutua imbricación entre el derecho a un medio ambiente sano y el derecho al desarrollo se proyectan de manera significativa en la configuración del bien jurídico protegido en el caso del primero de dichos derechos. Efectivamente, cuando se protege el medio ambiente desde el punto de vista jurídico, no se protege algo estático con la voluntad de preservar un estado natural de las cosas. Lo que se protege es una configuración dinámica del entorno físico que permite el desarrollo, en sentido pleno, de la vida humana y la realización progresiva de la aspiración a la calidad de vida, valor que también ha adquirido una dimensión jurídica a través de la evolución del Estado social y de sus documentos constitucionales (en este sentido, sirva como ejemplo la propia Constitución española) ${ }^{18}$.

El vector temporal aparece así como determinante en el caso del derecho al medio ambiente. En este sentido, de hecho, todos los derechos sociales tienen una vocación de progresión en el tiempo o adaptación social, que puede

16 Sobre la Declaración de Río, vid., particularmente, ALDER y WILKINSON, Environmental Law... cit., p. 113 ss.

17 Vid. COMISIÓN MUNDIAL DEL MEDIO AMBIENTE Y DEL DESARROLLO, Nuestro futuro común, Alianza Editorial, Madrid, 1988, p. 29. Sobre la noción de desarrollo sostenible, vid., particularmente, ALDER y WILKINSON, Environmental Law ... cit., p. 127 ss.; LOPERENA ROTA, Los principios... cit., p. 61 ss.; Nicolás M. SOSA, "A vueltas con la sustentabilidad, esta vez desde la ética", Sistema, n. 162/163, junio 2001, p. 57 ss.; Beatrice WAGNER PFEIFER, Umweltrecht (I), Schultess, Zúrich, 1999, pp. 29-30; y Bruno WALLIMANN, "Das schweizerische Umweltrecht auf der Höhe der Zeit", Umweltrecht in der Praxis / Le Droit de l'environnement dans la pratique, 1995 , p. 441.

$18 \mathrm{Vid}$. JARIA I MANZANO, El concepte constitucional... cit., p. 80 ss. 
apreciarse de manera explícita en algún texto constitucional (así, el artículo 9.2 de la Constitución española). Sin embargo, si en el caso de los derechos de segunda generación, la aspiración es la mejora progresiva de la condición humana, encajando plenamente en la cultura de la Ilustración, en el caso del derecho al medio ambiente, lo que se pretende es preservar para las generaciones futuras las condiciones para su propia supervivencia, respondiendo, por lo tanto, a una visión menos optimista sobre la condición humana que la que propugnaba el legado de la Ilustración.

\section{EL DERECHO A UN MEDIO AMBIENTE SANO EN DERECHO INTERNACIONAL}

A) Queda claro que, en el Derecho internacional, se ha manifestado una tendencia a considerar el medio ambiente como objeto de un derecho humano $^{19}$. Este fenómeno que ha ido cobrando fuerza con el transcurso del tiempo a partir, fundamentalmente, de la Declaración de Estocolmo de $1972^{20}$. Asimismo, dicho derecho tiende a proyectarse en aspectos concretos de otros derechos y, con ello, a influir de manera determinante en la configuración del catálogo general de derechos humanos reconocidos en los distintos niveles de protección a nivel internacional. Este fenómeno se da, particularmente, en el caso del Convenio Europeo de Derechos Humanos (CEDH), a través de la incorporación de variables ambientales al contenido del derecho a la vida privada y familiar del su artículo $8.1^{21}$.

Como se ha dicho, el momento inicial a partir de que el Derecho del medio ambiente y el derecho a un medio ambiente sano o adecuado se desarrolla en el plano internacional sería la Declaración de la Conferencia de las Naciones Unidas sobre el Medio Humano, aprobada en Estocolmo el 16 de junio de 1972. Previamente, no puede hablarse de una auténtica preocupación por la degradación ambiental, en la medida a que dicha preocupación responde a los problemas que genera el aumento de la capacidad de transformación del entorno físico por parte de los seres humanos a través del progreso tecnológico que se ha dado desde la Revolución industrial. Dichos efectos perniciosos de la evolución tecnológica no pasaron a formar parte de las preocupaciones sociales hasta los años sesenta del siglo pasado.

Pues bien, el principio primero de la Declaración de Estocolmo establece que el ser humano tiene un derecho fundamental "[a]l disfrute de condiciones

19 Vid. Susana BORRÀS PENTINAT, "La configuración de un nuevo derecho humano: el derecho humano al medio ambiente", Os novos conceitos do Novo Direito intentacional, America Jurídica, Río de Janeiro, 2002, pp. 453-468.

20 Sobre la Declaración de Estocolmo, vid. ALDER i WILKINSON, Environmental Law... cit., pp. 112-113.

21 De acuerdo con el artículo 8.1 CEDH, "[t]oda persona tiene derecho al respeto de su vida privada y familiar, de su domicilio y de su correspondencia". 
de vida adecuadas en un medio de calidad tal que le permita llevar una vida digna y gozar de bienestar, y tiene la solemne obligación de proteger y mejorar el medio para las generaciones presentes y futuras". Este reconocimiento es previo a la incorporación de dicho derecho a las constituciones estatales, lo que muestra el carácter pionero que el Derecho internacional público tiene en esta materia. Debe recordarse que dicho disfrute se sitúa, como derecho, en el mismo plano discursivo que la libertad y la igualdad que le preceden en el mencionado principio primero.

Como se ha dicho, posteriormente, el derecho al medio ambiente será acogido en otros documentos internacionales relativos a la protección de los derechos humanos, en este caso de carácter regional, como es el caso del protocolo adicional de la Convención Americana sobre Derechos Humanos en materia de derechos económicos, sociales y culturales o la Carta Africana de Derechos Humanos y de los Pueblos ${ }^{22}$. Este reconocimiento en documentos de carácter regional, unido a su progresiva constitucionalización (Europa del Sur, durante los años setenta; Europa Oriental y América Latina, entre los años ochenta y noventa), se proyectará en el contenido de la Declaración de Río, que asume lo que se disponía veinte años atrás en la Declaración de Estocolmo ${ }^{23}$.

La aportación más relevante de la Declaración de Río en el terreno de la configuración del medio ambiente adecuado o sano como objeto de un derecho es, aparte de la consagración del desarrollo sostenible como idea conductora de una estrategia de desarrollo a nivel planetario, la específica referencia a la dimensión procedimental del derecho, aludiendo tanto al derecho a la información, como a la legitimación procesal y a la participación en la toma de decisiones. Esta procedimentalización del derecho que se subraya en Río refuerza los argumentos de aquéllos que defienden la posibilidad de articular una auténtica exigibilidad jurídica para dicho derecho.

22 El artículo 11.1 del Protocolo adicional a la Convención Americana sobre Derechos Humanos en materia de derechos económicos, sociales y culturales, firmado en San Salvador el 17 de noviembre de 1988, dispone que "[t]oda persona tiene derecho a vivir en un medio ambiente sano y a contar con servicios públicos básicos". La Carta Africana de los Derechos Humanos y de los Pueblos, de 27 de junio de 1981, establece que "[t]odos los pueblos tendrán derecho a un entorno general satisfactorio favorable a su desarrollo".

23 Deben tenerse en cuenta, particularmente, los principios 1 y 10 de la Declaración de Río sobre el medio ambiente y el desarrollo. El principio primero afirma: «Los seres humanos constituyen el centro de las preocupaciones relacionadas con el desarrollo sostenible. Tienen derecho a una vida saludable y productiva en armonia con la naturaleza". Por su parte, el principio 10 establece lo siguiente: «El mejor modo de tratar las cuestiones ambientales es con la participación de todos los ciudadanos interesados, en el nivel que corresponda. En el plano nacional, toda persona deberá tener acceso adecuado a la información sobre el medio ambiente de que dispongan las autoridades públicas, incluida la información sobre los materiales y las actividades que encierran peligro en sus comunidades, así como la oportunidad de participar en los procesos de adopción de decisiones. Los Estados deberán facilitar y fomentar la sensibilización y la participación de la población poniendo la información a disposición de todos. Deberá proporcionarse acceso efectivo a los procedimientos judiciales y administrativos, entre éstos el resarcimiento de daños y los recursos pertinentes". La Declaración de Johannesburgo sobre Desarrollo Sostenible de 2002 no aporta novedades significativas en este terreno. 
B) En cualquier caso, debemos referirnos en este punto a la situación general en Europa en relación con el reconocimiento de dicho derecho, en la medida que ha sido en Europa donde se ha desarrollado un mayor acervo de Derecho supraestatal, a través, sobre todo, de la Unión Europea, pero, asimismo a través del Consejo de Europa. Este floreciente Derecho supraestatal también ha tenido su proyección el Derecho ambiental y, en particular, en relación con el proceso de configuración del derecho a un medio ambiente sano o adecuado, de lo que sería un ejemplo particular el mencionado Convenio de Aarhus.

En relación con el Convenio Europeo de Derechos Humanos, debemos referirnos a la ya citada jurisprudencia López Ostra. En diciembre de 1994, el Tribunal Europeo de Derechos Humanos culminaba un proceso de reinterpretación del mencionado Convenio para darle una significación ambiental de acuerdo la sensibilidad social que se había ido manifestando en los lustros precedentes. En aquella ocasión, el Tribunal condenó a España por una violación del artículo 8 del Convenio. Según el Tribunal, España no había protegido adecuadamente el derecho al respeto de la vida privada y familiar de la demandante, en la medida que casos serios de contaminación ambiental, aun sin causar problemas de salud, afectarían al bienestar de los individuos impidiéndoles disfrutar de su domicilio y, en consecuencia, violando el derecho reconocido en el convenio.

Esta "ambientalización" de los derechos reconocidos en el Convenio y, particularmente, del derecho al respeto de la vida privada y familiar se había ido preparando en los años previos la Sentencia López Ostra y ha recibido un significativo desarrollo posterior, con nuevas sentencias en el mismo sentido que han dado lugar a lo que podría calificarse como una jurisprudencia asentada, como muestra, recientemente, la Sentencia Moreno Gómez, de 2004, donde también se condena al Estado español por violación del derecho del artículo 8 del Convenio, en este caso, por un episodio de contaminación acústica ${ }^{24}$.

C) Por otra parte, en el ámbito de la Unión Europea, debe notarse que lo que se planteaba como un acuerdo de contenido fundamentalmente económico con el objetivo de crear un mercado común ha ido dotándose, progresivamente de contenido político, a través de documentos como el Acta Única (1986), el Tratado de Maastricht (1992) y el Tratado de Amsterdam (1997). La sensibilidad ambiental de las instituciones de la Unión ha sido muy significativa prácticamente desde los años setenta. De hecho, el punto de partida de la política ambiental comunitaria podría situarse en la Cumbre de París, en 1972, es decir, de manera coetánea a la Conferencia de Estocolmo ${ }^{25}$.

24 En relación con la "ambientalización" de los derechos fundamentales en el Convenio Europeo, vid. Blanca LOZANO CUTANDA, "La ecologización de los derechos fundamentales: la doctrina López Ostra c. España, Guerra y otros c. Italia y Hatton y otros c. Reino Unido del TEDH y su recepción por nuestro TC", Revista Española de Derecho Europeo, n. 1, enero-marzo 2002, p. 175-205.

25 Por supuesto, la bibliografía sobre el Derecho comunitario europeo en esta materia es inabarcable. Vid., sin embargo, como referencias básicas, Juan-Cruz ALLI ARANGUREN, "La evaluación de impacto ambiental en el Derecho comunitario", Revista de Derecho Urbanistico, n. 190, diciembre 2001, p. 143 ss.; José ÁLVAREZ DÍAZ, «De la politica medioambiental a la integración del 
Subsiguientemente, en 1973, se pone en marcha el Primer Programa de Acción en Medio Ambiente. A partir de ese momento, se han aprobado un numeroso grupo de directivas en materia de protección del medio ambiente que han condicionado la política ambiental de los estados miembros. La acción comunitaria se ha visto reforzada con la incorporación de la protección del medio ambiente y el compromiso con un desarrollo sostenible al Tratado de la Comunidad Europea. Así, el artículo 2, se refiere a la promoción de "un desarrollo armonioso, equilibrado y sostenible de las actividades económicas" así como a «un alto nivel de protección y de mejora de la calidad del medio ambiente" entre las misiones de la Comunidad.

La Carta de los Derechos Fundamentales de la Unión Europea, proclamada en Niza el 7 de diciembre de 2000, también hace una referencia a la protección del medio ambiente. Así, su artículo 37 prevé que "[l]as políticas de la Unión integrarán y garantizarán con arreglo al principio de desarrollo sostenible un alto nivel de protección del medio ambiente y la mejora de su calidad", de manera similar a lo previsto en el artículo 2 del Tratado de la Comunidad Europea. Sin embargo, como puede apreciarse, la Carta no ha dado el paso de reconocer un derecho en relación con la protección del medio ambiente y, de este modo, se ha ceñido a la prudencia manifestada en la mayoría de los sistemas jurídicos de los estados miembros en relación con ello. Esto no obsta, sin embargo, para que la Unión Europea siga jugando un papel activo en la protección del medio ambiente tanto en relación con sus estados

medio ambiente en las políticas sectoriales: la red de autoridades ambientales", Revista de Estudios Locales, n. Extraordinario dedicado al medio ambiente, julio 2001, p. 23 ss.; Marcello CECCHETTI, Principi costituzionali per la tutela dell'ambiente, Giuffrè, Milan, 2000, p. 23 ss.; James CONNELLY y Graham SMITH, Politics and the Environment. From theory to practice, Routledge, Londres, 1999, p. 217 ss.; DE MIGUEL PERALES, Derecho español... cit., p. 65 ss.; ESCOBAR ROCA, La ordenación constitucional... cit., p. 32 ss.; Dionisio FERNÁNDEZ DE GATTA SÁNCHEZ, "La política ambiental comunitaria en el Tratado de la Unión Europea", Revista de Estudios Europeos, n. 6, enero-marzo 1994, pp. 7-32; Rafael GARCÍA-VALDECASAS Y FERNÁNDEZ, "La protección del medio ambiente y el ordenamiento jurídico de la Comunidad Europea: La jurisprudencia del Tribunal de Justicia de Luxemburgo", Gerardo RUIZ-RICO RUIZ (coord.), Derecho comparado del medio ambiente y de los espacios naturales protegidos, Comares, Granada, 2000, pp. 1-38; Jan H. JANS, European Environmental Law, Kluwer, L'Haia-Londres-Boston, 1990, passim.; del mismo autor, "The Development of EC Environmental Law", Gerd WINTER (ed.), European Environmental Law. A Comparative Perspective, Darmouth, Aldershot-Brookfield-SingapurSydney, 1996, pp. 271-276; JORDÁ CAPITÁN, El Derecho... cit., p. 35 ss.; José JUSTE RUIZ, Derecho internacional del medio ambiente, McGraw-Hill, Madrid, 1999, p. 427 ss.; Fernando LÓPEZ RAMÓN, "Caracteres del Derecho comunitario europeo ambiental", Revista de Administración Pública, n. 142, enero-abril 1997, pp. 53 ss.; Lorenzo MARTÍN-RETORTILLO BAQUER, "Administración local y medio ambiente", José ESTEVE PARDO (coord.), Derecho del medio ambiente y administración local, Civitas, Madrid, 1996, p. 36 ss.; Luciano PAREJO ALFONSO, "Origen y desarrollo del Derecho medioambiental en el ordenamiento comunitario-europeo", Luciano PAREJO ALFONSO, Ludwig KRÄMER et al., Derecho medioambiental de la Unión Europea, McGrawHill, Madrid, 1996, pp. 41-69; Raphaël ROMI, Droit et administration de l'environnement, Montchrestien, París, 2004, p. 40 ss.; y Hans SOMSEN, "Derecho comunitario del medio ambiente: Tratado, instituciones, procedimiento de decisión e instrumento jurídico", PAREJO ALFONSO, KRÄMER et al., Derecho medioambiental... cit., pp. 1-39. 
miembros como en la escena internacional. En este contexto, la Carta de Derechos ha de jugar un papel clave como texto interpretativo del acervo comunitario para la jurisprudencia del Tribunal de Justicia de Luxemburgo.

Finalmente, la estrategia de dotar al derecho de un contenido procedimental, como se sugería en la Declaración de Río, hallará su desarrollo más conspicuo, hasta el momento, en el Convenio sobre el acceso a la información, la participación del público en la toma de decisiones y el acceso a la justicia, firmado en Aarhus el 25 de junio de 1998. Dicho convenio ha sido incorporado al Derecho de la Unión Europea a través con las directivas 2003/4/CE del Parlamento Europeo y del Consejo, de 28 de enero de 2003, relativa al acceso público a la información ambiental y por la que se deroga la Directiva 90/313/CEE del Consejo, y 2003/35/CE del Parlamento Europeo y del Consejo, de 26 de mayo de 2003, por la que se establecen medidas para la participación del público en la elaboración de determinados planes y programas relacionados con el medio ambiente y por la que se modifican, en aquello a que se refiere a la participación del público y el acceso a la justicia, las directivas 85/337/CE i 96/61/CE del Consejo.

Posteriormente, el legislador español ha incorporado el contenido de dichas directivas al ordenamiento jurídico interno a través de la Ley 27/2006, de 18 de julio, por la que se regulan los derechos de acceso a la información, de participación pública y de acceso a la justicia en materia de medio ambiente. Esta incorporación del contenido del Convenio de Aarhus de acuerdo con la formulación en que se ha efectuado su recepción en el Derecho comunitario, se producía prácticamente un año y medio después de que España hubiera ratificado el citado instrumento, el 29 de diciembre de $2004^{26}$.

Las consecuencias de dicho convenio a través de su recepción en el Derecho comunitario y en el Derecho español desde el punto de vista del despliegue del contenido del derecho a un medio ambiente sano y, particularmente, del artículo 45 de la Constitución, están aún por ver, pero está claro que, a partir de Río y Aarhus, el énfasis en la faceta procedimental del derecho es cada vez más evidente y, con ello, las oportunidades de dotarlo de una auténtica exigibilidad jurídica que supere las críticas a que ha sido sometido por una parte significativa de la literatura jurídico-constitucional desde la década de los setenta.

\section{EL RECONOCIMIENTO DE UN DERECHO A UN MEDIO AMBIENTE SANO EN LAS CONSTITUCIONES}

A partir de la Declaración de Estocolmo, la referencia al medio ambiente en el Derecho constitucional comparado fue generalizándose de manera progresiva. Sin embargo, es cierto que en aquellos lugares en que el Estado de

26 Para un comentario exhaustivo sobre la Ley 27/2006, vid. José Antonio RAZQUIN LIZARRAGA y Ángel RUIZ DE APODACA, Informacion, participacion y justicia en materia de medio ambiente. Comentario sistemático a la Ley 27/2006, de 18 de julio, Aranzandi, Cizur Menor, 2007. 
Derecho y, en consecuencia, la exigibilidad de las normas jurídicas era mayor, se mostraban más reticentes a incorporar cláusulas ambientales en las respectivas constituciones ${ }^{27}$. En este sentido, durante los años setenta, dejando aparte los nuevos documentos constitucionales correspondientes a las nuevas democracias parlamentarias del sur de Europa (por lo tanto, con una tradición de Estado de Derecho más bien irregular y poco desarrollada), los textos constitucionales que recogen disposiciones relacionadas con la protección del medio ambiente corresponden a estados socialistas.

En este sentido, deben mencionarse el artículo 31 de la Constitución búlgara de 1971, que consideraba la protección y la conservación de la naturaleza como obligaciones del Estado, así como, posteriormente, en el mismo sentido, la reforma de 1976 de la Constitución polaca de 1952 y la nueva Constitución soviética de $1977^{28}$. Fuera de Europa, pueden mencionarse los casos de la República Popular China o de $\mathrm{Cuba}^{29}$. Entre los textos con un Estado de Derecho consolidado sólo puede referenciarse el caso del Instrumento de Gobierno de 1974, que forma parte de la Constitución sueca, junto con otros documentos como el Acta de Sucesión ${ }^{30}$.

Dejando aparte el caso de las constituciones de Portugal, Grecia y España así como el caso específico de Suecia, nos encontramos ante constituciones semánticas, de acuerdo con la clasificación clásica de Loewenstein, es decir, que no gozaban de una aplicación jurídica real ${ }^{31}$. Esto permitía reconocer derechos sin que quedara claro cuál era su contenido jurídico, ya que se trataba de documentos de carácter meramente declarativo, destinados a presentar el proyecto ideológico del sistema político vigente, pero sin dar oportunidad a los ciudadanos de exigir su realización. De los casos excluidos, ni Grecia ni

27 Así cobra sentido la frase de Ronald DWORKIN, en Los derechos en serio, Ariel, Barcelona, 1995, p. 303, según la cual, "[s]i el Gobierno no se toma los derechos en serio, tampoco se está tomando con seriedad el Derecho".

28 En relación con el artículo 31 de la Constitución búlgara de 1971, vid. Giovanni CORDINI, Diritto ambientale comparato, Cedam, Padua, 1997, p. 74. En relación con la reforma citada de la Constitución polaca, vid. Eugenio ULL PONT, "La defensa del medio ambiente en la Constitución", Revista de Estudios Políticos, n. 5 (nueva época), septiembre-octubre 1978, p. 159. Sobre el texto soviético, vid. CORDINI, Diritto ambientale comparato cit., p. 75; Javier DOMPER FERRANDO, El medio ambiente y la intervención administrativa de las actividades clasificadas. I. Planteamientos constitucionales, Civitas, Madrid, 1992, p. 94; y Pedro M. LARUMBE BIURRUN, "Medio ambiente y comunidades autónomas", Revista Vasca de Administración Pública / Herri-Arduralaritzazko Euskal Aldizkaria, n. 8, ener-abril 1984, p. 27.

29 Sobre el texto de la Constitución china en esta materia, vid. CORDINI, Diritto ambientale comparato cit., p. 75. Sobre el texto cubano, vid. ULL PONT, "La defensa..." cit., p. 160.

30 Vid. Giovanni CORDINI, Diritto ambientale. Elementi giuridici comparati della protezione ambientale, Cedam, Padua, 1995, p. 36. En la versión actual, existe una referencia al medio ambiente en el artículo 2 del capítulo I, donde se dice: “Los poderes públicos deben promover el desarrollo sostenible para conseguir un medio ambiente adecuado para la presente y las futuras generaciones" (versión a partir de la existe en inglés en la web del Parlamento sueco, http://www.riksdagen.se).

31 Vid. Karl LOEWENSTEIN, Teoria de la Constitución, Ariel, Barcelona, 19762 (edición castellana a cargo de Alfredo Gallego Anabitarte), pp. 217-222 
Suecia se refieren, en cualquier caso, a un derecho individual, lo que sólo se da en Portugal y de España. Esto ha generado una problemática específica a la hora de garantizar sus cláusulas en relación con la protección del medio ambiente.

Esta situación, que se da desde los años setenta, muestra que no basta el reconocimiento de algún tipo de derecho en relación con la protección del medio ambiente para garantizar que se llegue a un nivel de protección efectivo. En realidad, en la mayoría de casos, los estados con un nivel de protección más elevado son los que más reservas plantean al reconocimiento de derechos constitucionales en esta materia, mientras que otros se limitan a un reconocimiento formal en documentos constitucionales de dudosa efectividad $\mathrm{y}$, en consecuencia, la protección que recibe el bien jurídico es inferior.

La situación planteada, sin embargo, parece apuntar a una evolución hacia un reconocimiento efectivo de un derecho a un medio ambiente sano. Podría decirse que, mientras los estados con ordenamientos jurídicos con mayor eficacia real, avanzan con prudencia hacia ese reconocimiento, afinando progresivamente los instrumentos de protección, los estados que provienen de una tradición constitucional basada en documentos generalmente de tipo semántico van dotando progresivamente de contenido los derechos ambientales ya reconocidos en sus constituciones. Esta visión optimista de las cosas responde, fundamentalmente, a los logros alcanzados en el terreno internacional en los últimos treinta años, que, aunque puedan parecer insuficientes para algunos, representan un avance importantísimo en el nivel de compromiso en un período de tiempo relativamente corto.

Los síntomas de una evolución progresiva, desde puntos de partida distintos, en la línea de un reconocimiento efectivo de algún tipo de derecho en relación con la protección del medio ambiente se manifiestan tanto en aquellos sistemas con un Estado de Derecho más consolidado y de mayor raíz histórica como en aquellos que se encuentran aún en una fase de construcción, recuperación o desarrollo de ese tipo de Estado (más avanzada en América Latina y en la Europa Oriental; menos, en África).

Pueden citarse diferentes ejemplos. Así, en Italia, la Corte Costituzionale ha reconocido, desde su sentencia 210/1987, de 22 de mayo, la existencia de un derecho fundamental al medio ambiente implícito en la Constitución de $1947^{32}$. En Alemania, el reconocimiento implícito de algún tipo de derecho en relación con el medio ambiente ha tenido un cierto desarrollo doctrinal, particularmente antes de la introducción del actual artículo 20a de la Ley Fundamental de Bonn en 1993, aunque, finalmente, la ausencia de cualquier tipo de derecho en dicha disposición ha enfriado, en cierto modo el debate ${ }^{33}$. Tam-

32 Puede consultarse esta sentencia en la página web de la Corte Costituzionale (http://www.cortecostituzionale.it).

33 En relación con esto, vid. Fernando LÓPEZ RAMÓN, "Derechos fundamentales, subjetivos y colectivos al medio ambiente", a Revista Española de Derecho Administrativo, n. 95, julio-septiembre 1997, p. 352. 
bién se ha producido un reconocimiento a nivel legislativo en Estados Unidos con la National Environmental Protection Act, que entró en vigor en $1970^{34}$. Por otra parte, en el caso de Estados Unidos, debe tenerse en cuenta que algunos de los estados, como por ejemplo Illinois, ya han introducido el derecho a un medio ambiente sano o adecuado en sus respectivas constituciones ${ }^{35}$.

Por otro lado, el proceso de constitucionalización de algún tipo de derecho en relación con el medio ambiente ha recibido un impulso cada vez mayor a medida que los estados que, saliendo de diversos tipos de experiencias autoritarias o totalitarias, se dotaban de un sistema democrático y constitucional iban redactando sus nuevas cartas magnas de acuerdo con las tendencias de evolución en el reconocimiento de los derechos humanos en el plano internacional. De este modo, en el caso de América Latina, podemos referirnos a las constituciones de Brasil o de Colombia ${ }^{36}$. Argentina, en 1994, así como México, en 1999, también incluyeron disposiciones en el mismo sentido $^{37}$. Asimismo, el artículo 19.8 de la Constitución de Chile reconoce a

34 Sobre el contenido de la NEPA, vid., particularmente, Susan J. BUCK, Understanding Environmental Administration and Law, Island, Washington-Covelo, 1991, p. 19 ss.; Nancy K. KUBASEK y Gary S. SILVERMAN, Environmental Law, Prentice Hall, Upper Saddle River, 20003, p. 130 ss.; y Yves NICOLE, L'étude d'impact dans le système fédéraliste suisse. Etude de droit fédéral et de droit vaudois, Payot, Lausanne, 1992, p. 25 ss. La sección 101.c de la NEPA, dispone que «[t]he Congress recognizes that each person should enjoy a healthful environment and that each person has a responsibility to contribute to the preservation and enhancement of the environment".

35 Para el texto de la Constitución del estado de Illinois, puede consultarse la página web de la Asamblea Legislativa de dicho estado (http://www.ilga.gov/).

36 El artículo 225 de la Constitución de la República Federal de Brasil de 1988 proclama: "Todos tienen derecho a un medio ambiente ecológicamente equilibrado, bien de uso común del pueblo y esencial para una sana calidad de vida, imponiéndose al Poder Público y ala colectividad el deber de defenderlo y preservarlo para las generaciones presentes y futuras". Para el texto de la Constitución brasileña hemos utilizado la versión original en portugués que puede consultarse en la página web de la Base de Datos Políticos de las Américas, que elaboran la Georgetown University y la Organización de Estados Americanos (http://www.georgetown.edu/pdba). Sobre el texto constitucional brasileño, vid. Sobre Brasil, vid. JORDÁ CAPITÁN, El Derecho... cit., p. 89 ss.; LOPERENA ROTA, Los principios... cit., pp. 44-45; MARTÍN-RETORTILLO BAQUER, "Administración local...” cit., p. 35; y RUIZ-RICO RUIZ, El derecho... cit., pp. 37-38. Por su parte, el artículo 79 de la Constitución Política de la República de Colombia de 1991. establece lo siguiente: "Todas las personas tienen derecho a gozar de un ambiente sano". La fuente utilizada para este texto es la misma que en el caso anterior. Sobre el tratamiento del medio ambiente en la Constitución colombiana, vid. RUIZ-RICO RUIZ, El derecho... cit., p. 39 ss.; y Sandra MORELLI, "La protección de la diversidad e integridad del ambiente: un mandato constitucional en el Derecho colombiano", a RUIZ-RICO RUIZ, Derecho comparado... cit., p. 331 ss. Según el primero de los autores citados, cabe calificar la Constitución colombiana, por la amplitud de las referencias a la protección del medio ambiente, como una "Constitución ecológica".

37 Sobre Argentina, vid., en general, Alberto Ricardo DALLA VIA, a "Derecho ambiental en Argentina: la reforma constitucional de 1994 y el medio ambiente", RUIZ-RICO RUIZ, Derecho comparado... cit., pp. 286-306. Además, en la literatura española, hacen referencia al tratamiento del medio ambiente en la Constitución argentina, Fernando LÓPEZ RAMÓN, "Derechos fundamentales, subjetivos y colectivos al medio ambiente", Revista Española de Derecho Administrativo, n. 95, julio-septiembre 1997, p. 350; y RUIZ-RICO RUIZ, El derecho... cit., p. 32 ss. Sobre México, vid. Marisela CIFUENTES LÓPEZ y Saúl CIFUENTES LÓPEZ, "El derecho constitucional a un medio ambiente adecuado en México", RUIZ-RICO RUIZ, Derecho comparado... cit., pp. 427-445. 
todas las personas "[e]l derecho a vivir en un medio ambiente libre de contaminación, ${ }^{38}$.

Nos hallamos, sin embargo, ante ordenamientos jurídicos que tienen aún un cierto déficit de efectividad real en la mayoría de los casos, aunque, probablemente, esto va corrigiéndose progresivamente. De este modo, la evolución del reconocimiento del derecho a un medio ambiente sano o adecuado parece abogar por la tesis que aquí se sostiene. Esto es, aquellos estados con un mayor nivel de eficacia de su Derecho tienden progresivamente a reconocer un derecho a un medio ambiente sano o adecuado, mientras que aquellos con un menor nivel de eficacia, tienden a aumentarlo y, en consecuencia, a aumentar las posibilidades de exigibilidad jurídica de un derecho que ya reconocen en sus respectivas constituciones.

Sin salir de América Latina, el caso de Costa Rica tiene una significación particular. Así, la Reforma Constitucional 7412, de 3 de junio de 1994, introdujo un nuevo párrafo en el artículo 50 de la Constitución de 1949, de acuerdo con el cual, "[t]oda persona tiene derecho a un ambiente sano y ecológicamente equilibrado. Por ello, está legitimada para denunciar los actos que infrinjan ese derecho y para reclamar la reparación del daño causado "39. Más allá del reconocimiento del mencionado derecho, el mismo artículo, en su último apartado, dispone que «e]l Estado garantizará, defenderá y preservará ese derecho. La ley determinará las responsabilidades y las sanciones correspondientes". De modo que se reconoce un derecho junto a un principio rector ${ }^{40}$. El caso de Costa Rica es singular en la medida que no se trata de un estado que salga de una experiencia dictatorial y, en cambio, de acuerdo con la tendencia que se manifiesta en el conjunto del continente, incorpora el derecho

38 El texto citado se cita conforme a la versión que figura en la Base de Datos Políticos de las Américas, que elaboran la Georgetown University y la Organización de Estados Americanos (http://www.georgetown.edu/pdba). De acuerdo con el artículo 20, procederá el recurso de protección ante la Corte de Apelaciones, en el caso de violaciones del artículo 19.8, "cuando el derecho a vivir en un medio ambiente libre de contaminación sea afectado por un acto arbitrario e ilegal imputable a una autoridad o persona determinada" (citado conforme a la misma fuente). Sobre la Constitución chilena y la protección del medio ambiente, José Antonio RAMÍREZ ARRAYÁS, "Derecho ambiental en Chile: principales elementos de la institucionalidad e interpretación jurisdiccional de la evaluación ambiental", RUIZ-RICO RUIZ, Derecho comparado... cit., pp. 201-202.

39 Se cita el texto constitucional costaricense de acuerdo con la versión que figura en la página web de la Asamblea Legislativa de Costa Rica (http://www.asamblea.go.cr/).

40 Otros estados centroamericanos se refieren a la protección del medio ambiente sólo en tanto que principio rector o mandato a los poderes públicos, sin considerar ningún derecho en relación con ello. Este sería el caso de la Constitución panameña, cuyo artículo 114 establece: «Es deber fundamental del Estado garantizar que la población viva en un ambiente sano y libre de contaminación, en donde el aire, el agua y los alimentos satisfagan los requerimientos del desarrollo adecuado de la vida humana". Por su parte, el artículo 115 de la misma Constitución, proclama que "[e]l Estado y todos los habitantes del territorio nacional tienen el deben de propiciar un desarrollo social y económico que prevenga la contaminación del ambiente, mantenga el equilibrio ecológico y evite la destrucción de los ecosistemas" (citado de acuerdo con la versión que figura en la Base de Datos Políticos de las Américas, que elaboran la Georgetown University y la Organización de Estados Americanos, en la dirección ya citada: http://www.georgetown.edu/pdba). 
a un medio ambiente sano en su texto constitucional, colocándose, de este modo, a la vanguardia del proceso de evolución a que nos referimos. Este caso es particularmente significativo si se le compara con la reticencia que han tenido los sistemas europeos con un Estado de derecho consolidado para dar el mismo paso, como puede apreciarse, particularmente en el debate académico que precede a la reforma de la Ley Fundamental de Bonn del mismo año, de 1994, que introduce el nuevo artículo 20a, relativo a la protección del medio ambiente pero sin ninguna referencia a un derecho ${ }^{41}$.

Lo que se observa en América Latina, se reproduce, de algún modo, en las constituciones de los estados de la Europa central y oriental aprobadas después de la caída de los respectivos regímenes comunistas. En este caso, parece que el reconocimiento meramente declarativo que podía encontrarse en algunas de las constituciones de los sistemas de socialismo real, a las que ya nos hemos referido, es sustituido por un reconocimiento con vocación de efectividad en los nuevos documentos constitucionales. En este sentido, deben mencionarse la Constitución de Bulgaria (1991) y la de Eslovaquia (1992), así como la Carta de Derechos y Libertades de la República Checa (1992), que goza de rango constitucional ${ }^{42}$.

En este repaso al tratamiento del derecho a un medio ambiente sano en el contexto del constitucionalismo comparado, merecen especial atención los textos constitucionales de Grecia, Portugal y España. El artículo 24.1 de la Constitución griega de 1975 supone la primera regulación constitucional profunda a nivel comparado de la problemática ambiental una vez esta se manifiesta como un elemento de interés para las sociedades contemporáneas ${ }^{43}$. El texto portugués da un paso adelante y reconoce, por fin, un derecho individual en este campo. Así, el artículo 66.1 de la Constitución portuguesa de

41 En general, sobre dicho debate, vid. J. JARIA I MANZANO, El sistema constitucional... cit., p. 177 ss. Sobre la oposición de parte de la doctrina alemana al reconocimiento de algún tipo de derecho subjetivo en relación con la protección del medio ambiente en el debate que condujo a la introducción del artículo 20aGG, vid., particularmente, Christian CALLIESS, Rechtsstaat und Umweltstaat, Mohr Siebeck, Tubinga, 2001, p. 105; y Ulrich KARPEN, "Zu einem Grundrecht auf Umweltschutz", Werner THIEME (ed.), Umweltschutz im Recht, Duncker \& Humblot, Berlín, 1988, p. 22.

42 Para los textos de dichos documentos constitucionales, vid. CORDINI, Diritto ambientale comparato cit., p. 79. Por otra parte, debe considerarse el tratamiento constitucional de la cuestión ambiental en el texto polaco de 1997, que constituye una Constitución particularmente ambiciosa en este terreno, aunque no reconoce ningún tipo de derecho individual en relación con la protección del medio ambiente. Así, la Constitución polaca de 1997 establece entre los fines del Estado, en su artículo 5, la protección del medio ambiente según los principios del desarrollo sostenible. En el artículo 31, se cita la protección del medio ambiente como una finalidad del Estado que puede hacer necesaria la limitación de los derechos individuales. Finalmente, el artículo 74.2 establece: "La protección del medio ambiente será un deber de los poderes públicos". En cualquier caso, si bien no se menciona en general un derecho en relación con la protección del medio ambiente, el texto polaco garantiza en el artículo 74.3 un derecho de información en relación con el medio ambiente. Para las citas hemos utilizado la versión en inglés que ofrece la página web de la Cancillería del Primer Ministro (http://www.kprm.gov.pl/s).

43 Para una bibliografía fundamental sobre este aspecto de la Constitución griega, vid. las referencias que se citan en la nota 9. 
1976 reconoce a todos el «derecho a un ambiente humano de vida, salubre y ecológicamente equilibrado y el deber de defenderlo" ${ }^{44}$. Por su parte, como es sabido, la Constitución española establece que "[t]odos tienen el derecho a disfrutar de un medio ambiente adecuado para el desarrollo de la persona, así como el deber de conservarlo". En el caso español, por otra parte, deben mencionarse las recientes reformas de estatutos de autonomía que han trasladado el reconocimiento de algún tipo de derecho en relación con el medio ambiente al nivel autonómico. En este sentido, hay que destacar, particularmente el artículo 27 del nuevo Estatuto de Autonomía de Cataluña (2006) y el artículo 28 del nuevo Estatuto de Autonomía de Andalucía (2007).

\section{CONCLUSIÓN}

El panorama presentado en las páginas precedentes sirve para apreciar que, a pesar de las dificultades significativas que ha presentado su progresiva construcción en el ámbito de la dogmática jurídico-pública, el derecho a un medio ambiente sano o adecuado va consolidándose como un derecho reconocido tanto en el Derecho internacional público como en el Derecho constitucional interno. La progresiva construcción de un contenido jurídicamente exigible de dicho derecho favorece dicho proceso, aunque no se abandona su formulación más general como un mero principio rector. De este modo, los estados que más reservas han manifestado en relación con su reconocimiento van avanzando hacia la aceptación de este derecho, de entrada en un plano legislativo, mientras que aquellos que lo han reconocido más entusiásticamente, pero sin garantías reales, progresan en su exigibilidad.

Existen dos aproximaciones fundamentales al sentido del que puede dotarse el derecho a un medio ambiente sano o adecuado. Por una parte, puede hablarse de un enfoque defensivo, que pretende dotar a los individuos de instrumentos jurídicos para reaccionar ante agresiones concretas al medio ambiente que les afectan directamente. Una variante particularmente interesante de este caso se da cuando el titular del derecho, a saber, cualquier persona física, puede instar los mecanismos de control de la actividad de los poderes públicos previstos en el ordenamiento jurídico ante una decisión que afecta al medio ambiente, partiendo de la legitimidad que le otorga disfrutar constitucionalmente del derecho a un medio ambiente sano o adecuado.

En este sentido, como apunta Michel Bélanger para el caso de Canadá, el reconocimiento constitucional de algún tipo de derecho en relación con la protección del medio ambiente puede ser utilizado por los tribunales como canon para el control de la actividad de los poderes públicos, en base a la supremacía de la Constitución ${ }^{45}$. En la medida que los individuos puedan instar

44 En relación con ello, vid. las referencias citadas en la nota 9.

45 Vid. Michel BÉLANGER, La reconnaissance d'un droit fondamental à un environnement de qualité, Thémis, Montréal, 1990, p. 61. 
procesalmente dicho control, podrán aducir para ello el derecho en relación con el medio ambiente que les haya sido constitucionalmente reconocido ${ }^{46}$. Lo que sería exigible, en este caso, es el respeto por parte de los poderes públicos de unos límites fundamentales, derivados de la Constitución, en relación con el medio ambiente, lo que se proyectaría, particularmente, por ejemplo, en el control de la intervención administrativa en múltiples sectores de actividad.

Por otra parte, puede delimitarse una significación cooperativa de dicho derecho, cuya finalidad es dotar a los individuos de acceso al proceso de toma de decisiones. Hacia esta faceta del derecho apunta particularmente el ya citado Convenio de Aarhus. En este caso, el sujeto (persona física) puede exigir intervenir en la toma de decisiones que afecten al medio ambiente ${ }^{47}$. Como en el caso anterior, el sujeto obligado son los poderes públicos. Esta segunda aproximación se vincula con el principio de precaución, destinado a evitar ex ante los daños que puedan amenazar al medio ambiente ${ }^{48}$. Ello permite el desarrollo de una política ambiental más segura y menos controvertida, en la medida que deriva de un proceso de participación ciudadana. En este sentido, la construcción de un derecho humano en este terreno apunta consecuencias prometedoras en la implementación de un modelo de desarrollo respetuoso con el medio ambiente y ajustado a las inquietudes y necesidades de una determinada sociedad.

Hacia ello apunta el proceso de articulación jurídica de un derecho a un medio ambiente adecuado que intenta integrar necesidades sociales no subsumibles en los esquemas clásicos del derecho público subjetivo. Este proceso no es sencillo, pero, en cualquier caso, una configuración dogmáticamente sostenible y prácticamente eficaz del derecho a un medio ambiente sano es

46 Este argumento se desarrolla en JARIA I MANZANO, El sistema constitucional... cit., p. 200 ss.

47 En un caso y en otro hemos hablado de la persona física como titular. Sin embargo, en la mayor parte de ocasiones es más operativo que personas jurídicas cuyo objeto constituye precisamente la salvaguarda del medio ambiente puedan intervenir procesalmente para exigir el cumplimiento de las obligaciones que derivan del reconocimiento de algún tipo de derecho en relación con la protección del medio ambiente. No es que dichas organizaciones, sin embargo, sean titulares del derecho, sino que, por así decir, actúan en interés de los auténticos titulares, las personas físicas, que son las que realmente son afectadas por las actividades que inciden en el medio ambiente.

48 Sobre el principio de precaución, vid. Jamie BENIDICKSON, Environmental Law, Irwin Law, Ottawa, 1997, p. 18; CALLIESS, Rechtsstaat... cit., p. 153 ss.; Marcello CECCHETTI, Princip $i$ costituzionali per la tutela dell'ambiente, Giuffrè, Milán, 2000, p. 169 ss.; Nicolas DE SADELEER, "Reflexiones sobre el estatuto jurídico del principio de precaución", Revista de Derecho Ambiental, n. 25, 2000, p. 91 ss.; Astrid EPINEY, Hanspeter PFENNIGER y Reto GRUBER, Europäisches Umweltrecht und die Schweiz. Neuere Entwicklungen und ibre Implikationen, Stämpfli, Berna, 1999, p. 32 ss.; Wilfried ERBGUTH, Rechtssystematische Grundfragen des Umweltrechts, Duncker \& Humblot, Berlín, 1987, p. 92 ss.; Helene KELLER, Umwelt und Verfassung. Eine Darstellung des kantonalen Umweltverfassungsrechts, Schultess, Zuric, 1993, p. 169; Dominik KOECHLIN, Das Vorsorgeprinzip im Umweltschutzgesetz unter besonderer Berücksichtigung der Emissions - und Immissionsgrenzwerte, Helbing \& Lichtenhahn, Basilea-Frankfurt am Main, 1989, p. 10 ss. 
algo que está cada vez más cerca. Así, los diferentes sistemas jurídicos van camino de encontrar un vehículo de grandes posibilidades para responder a los conflictos sociales vinculados a la tensión entre el desarrollo y la protección del medio ambiente.

ABSTRACT. During the last three decades the recognition of some kind of rights about environmental protection has been developed around the world, in international public law as in internal constitutional law. Despite this, it has been a excruciating question to define the content of this kind of rights. The general category of the right to a bealthy environment receives a different treatment in different legal systems and has a complex set of facets hard to be insert into an unity.

This work try to describe the situation of the recognition of the right to a healthy environment in the international and the national level with the final aim of state that this situation of fact demands to define a legal content of it, despite the difficulties that have been noted by the scholars, tending to underline the impossibility of give to it a real legal status. We are facing a legal reality answering with more or less success to social needs and it is required to accept the process of general recognition of the right and to extract conclusions of this.

After the presentation of the status of the situation in international main documents and significant constitutions, the work makes a proposal to give content to the right to a healthy environment in a double sense. First, we have a defensive approach, which aims to give individuals the legal weapons to react against actual aggressions that affect them directly; and second, we have the cooperative point of view, which aims to give them access to the decision-making process. The first approach more or less reacts to actual harm. The second is intended to prevent harm. This could be a starting point to advance in define a legal content of this right. 